\title{
Moisture retention and plasticity of highly calcareous soils in Egypt
}

\author{
W. P. Stakman' ${ }^{1}$ and B. G. Bishay ${ }^{2}$ \\ 1 Institute for Land and Water Management Research (ICW), Wageningen, the \\ Netherlands \\ ${ }^{2}$ Land and Water Research Institute, Giza, Egypt
}

Accepted: 17 September 1975

Index words: moisture retention, soil plasticity, soil consistency limits, calcium carbonate, particle size distribution

\section{Summary}

Of six differently textured highly calcareous soils from the northwestern area of Lower Egypt, having $\mathrm{CaCO}_{3}$ contents ranging from 25 to $61 \%$ and containing attapulgite as the main clay mineral, $\mathrm{CaCO}_{3}$ distribution, particle size distribution, moisture retention curves and consistency limits were determined. As far as possible the same properties were investigated after decalcification of the samples.

The $\mathrm{CaCO}_{3}$ of the clay and clay loam soils was predominantly in the silt and clay fraction, the latter containing the major part. In the sandy loam it was rather regularly distributed over the clay, silt and sand fractions, and in the loamy sand the sand fraction held the greater part.

Decalcification shifted the particle size distribution to a coarser textured class and caused an increase in porosity and generally an increase in moisture content over the whole suction range. Physical changes after decalcification may not only be attributed to a change in texture but also to a change in structure of the attapulgite mineral.

Liquid limit and plasticity index increased with increasing clay and $\mathrm{CaCO}_{3}$ contents up to approximately $40 \%$ clay and $35 \% \mathrm{CaCO}_{3}$. The plastic limit stayed rather constant at increasing clay and $\mathrm{CaCO}_{3}$ contents. The soils appeared to belong to the low to medium plasticity categories. The liquid limit corresponded with suctions of $\mathrm{pF} 1.3$ to 1.9 within the flex range from the saturated to the unsaturated condition of the pF curves. The plastic limit and the plasticity index corresponded with $\mathrm{pF} 2.1$ to 3.0 and $\mathrm{pF} 2.6$ to 3.8 , respectively. The last-mentioned values were in good agreement with the plasticity index-pF relationships found by Livneh et al. (1970) for clayey and loamy soils.

All the investigated highly calcareous soils showed low clay activities. 


\section{Introduction}

In the western coastal zone of Lower Egypt marine-lacustrine plain soils occur, in the north bordered by a zone with rocky beach ridges, running parallel to the coast. Between these ridges flat stretches of salinas are present showing similar characteristics as the marine-lacustrine soils. The marine coastal beach ridges were formed throughout the Pleistocene in successive periods of high sea levels. In first instance they were formed under water but emerged during subsequent periods of lower sea levels. In a period of higher sea levels the former beach plain was again submerged and became a lagoon protected from the direct influence of the sea by the coastal ridges. Loamy and clayey sediments were deposited in the lagoon. During later periods these marine and salina deposits, after having been left dry, were often covered by silt loam material washed down from the ridges. The older ridges, though originally consisting of loose material, consist of more or less hard limestone material. Nowadays a succession of five high ridges parallel to the present coast line typifies the coastal area of Egypt westward of Alexandria.

The soils on the ridges nearest to the sea - the two younger beach ridges - are sandy; inland on the older beach ridges they become more loamy and are fine or even heavy textured. The flat areas between the ridges contain heavier textured soils. Both the marine-lacustrine soils and the salinas between the older beach ridges offer great possibilities for reclamation and development of irrigated agriculture, which is in progress nowadays (UNDP/FAO, 1965).

Both heavier and lighter soils of the coastal area are very rich in lime (up to $60 \%$ ). Furthermore the marine-lacustrine soils are often marked by the presence of the clay mineral attapulgite, which belongs to the family of palygorskites (Millot, 1964).

It generally is accepted that attapulgite is of lacustrine origin formed by basic sedimentation in arid and semi-arid periods as did occur in the fluctuating Pleistocene climate (Elgabaly, 1962; Millot, 1964; Labib \& Sys, 1970; McLean et al., 1972).

In spite of the large number of publications on soil-water relationships issued during the last three decades, there is scarcely any information on the soil physical properties of highly calcareous soils (de Meester, 1971) and on soils containing attapulgite. This paper deals with the effect of calcium carbonate, particle size and the influence of attapulgite clay mineral on the water retention properties and consistency indices of some highly calcareous soils in Egypt.

\section{Materials and methods}

\section{Soils}

Six soil samples were collected from the northwestern part of Egypt, west and southwest of Alexandria (Fig. 1). Soil class, location and depth of sampling were as follows:

Soil 1: sandy loam, El-Nobaria location, depth $0-10 \mathrm{~cm}$;

Soil 2: loamy sand, El-Nobaria location, depth $15-30 \mathrm{~cm}$;

Soil 3: clay, El-Nobaria location, depth $20-30 \mathrm{~cm}$; 


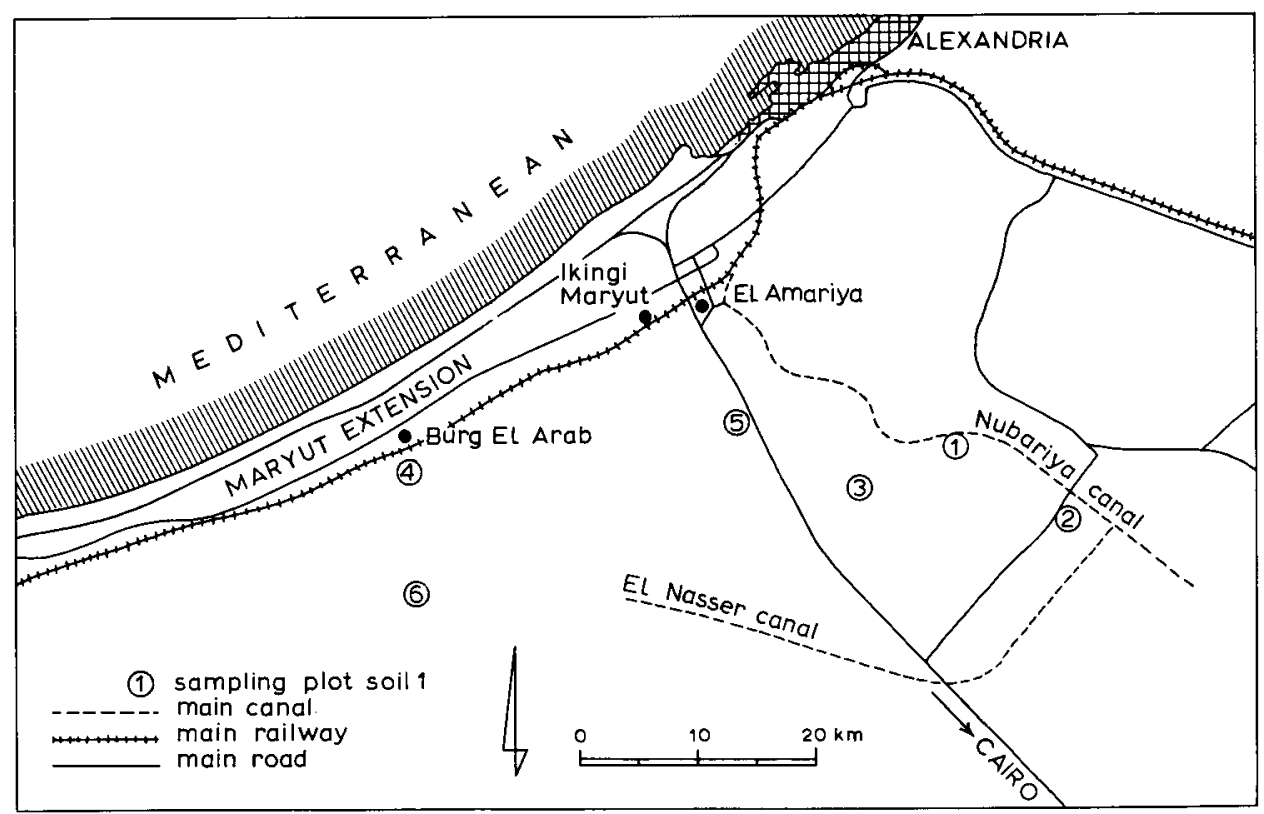

Fig. 1. Location of sampling plots in the northwestern area of Lower Egypt; 1: sandy loam; 2: loamy sand; 3 : clay; 4,5 and 6: clay loam.

Soil 4: clay loam, Burg-el-Arab location, between the 3rd and 4th old dune ridge, depth $80-90 \mathrm{~cm}$;

Soil 5: clay loam, Amariya location along road Alexandria-Cairo, depth $30-40 \mathrm{~cm}$; Soil 6: clay loam, Burg-el-Arab location far south of 4th old dune ridge, depth $10-20 \mathrm{~cm}$.

Organic matter content of the soils was less than $0.4 \%$. Mineralogical analysis of the samples revealed that all of them contained large quantities of calcite and dolomite. After removal of lime the main clay mineral present appeared to be attapulgite and a certain amount of kaolin. Further examination of the clay loams 4 to 6 proved that attapulgite and kaolin were present in quantities of 60-80 and of $10-30 \%$, respectively. ${ }^{1}$

Each soil sample was air-dried and passed through a $2-\mathrm{mm}$ sieve. The following determinations were carried out.

\section{Particle size distribution}

For segregating particles coarscr than $50 \mu \mathrm{m}$ the sieving method was used. For the finer particles the pipette sampling method was applied (Black, 1954) with sodium tripolyphosphate as dispersing agent without eliminating the calcium carbonate.

1 The authors wish to express their thanks to Dr L. van der Plas, Department of Soil Science and Geology, Agricultural University, Wageningen, for the mineralogical analysis of the samples. 
As appears from research on calcareous and saline-alkali soils, sodium tripolyphosphate is to be preferred as dispersing agent for mechanical analysis (UNDP/FAO, 1965, Vol. 4, App. 2; Deb \& Chadha, 1970).

\section{Calcium carbonate content}

The calcium carbonate content was calculated from the measured volume of carbonic gas exsolved from the soil sample by adding $25 \%$ hydrochloric acid (Scheibler method).

The calcium carbonate content of each of the textural fractions was determined by the acid neutralization method (Richards, 1954).

\section{Soil moisture retention curves}

For the suction range 0 to 0.5 atmosphere stainless steel cylinders (length $51 \mathrm{~mm}$, inside diameter $50 \mathrm{~mm}$, capacity $100 \mathrm{~cm}^{3}$ ) were filled with dry soil by tapping and using a rubber stopper of nearly the same diameter to attain a more or less natural compaction.

The samples were placed on the sand-box apparatus, presaturated and subjected to suctions of $2.5,10.0,31.6,63.1$ and $100 \mathrm{~cm}$ water column (pF 0.4, 1.0, 1.5, 1.8 and 2.0). After that the sand-kaolin box was used for suctions of 200 and $500 \mathrm{~cm}$ water column (pF 2.3 and 2.7) (Stakman et al., 1969).

The 15 atmosphere percentage $(\mathrm{pF} 4.2)$ was determined with a pressure membrane apparatus with a cellophane P.T. 600 membrane, on which the presaturated soil was filled in plastic rings (height $10 \mathrm{~mm}$, diameter $33 \mathrm{~mm}$ ) (Stakman \& van der Harst, 1969).

\section{Consistency limits or Atterberg limits}

The liquid and plastic limits were determined on air-dry soils, after which the plasticity index was calculated. The procedure is described by Lambe (1960). It was not possible to determine the limits of soil 2 because of its very low clay content $(8.4 \%)$.

Particle size distribution and moisture retention curves also were determined by taking identical soil samples of which the calcium carbonate was removed by means of diluted hydrochloric acid (Richards, 1954). The determination of Atterberg limits on the decalcified soils failed to yield reproducible results.

\section{Particle size and $\mathrm{CaCO}_{3}$-distribution}

The particle size analysis of the original soils and of the soils after removal of $\mathrm{CaCO}_{3}$ is shown in Table 1.

Removal of $\mathrm{CaCO}_{3}$ diminishes the clay fraction $(<2 \mu \mathrm{m})$ and the fine and medium silt fraction $(2-16 \mu \mathrm{m})$ considerably, particularly in the heavier soils 3,4 and 6 , whereas the coarse silt fraction $(16-50 \mu \mathrm{m})$ and the sand fraction $(>50 \mu \mathrm{m})$ are increased. Clay loam 5 shows only a great decrease in the clay fraction $(<2 \mu \mathrm{m})$ and an increase in nearly all other fractions after removal of $\mathrm{CaCO}_{3}$. On the other hand decalcification only slightly affects the clay, silt and sand particle size distribution of the lighter textured soils 1 and 2 . 


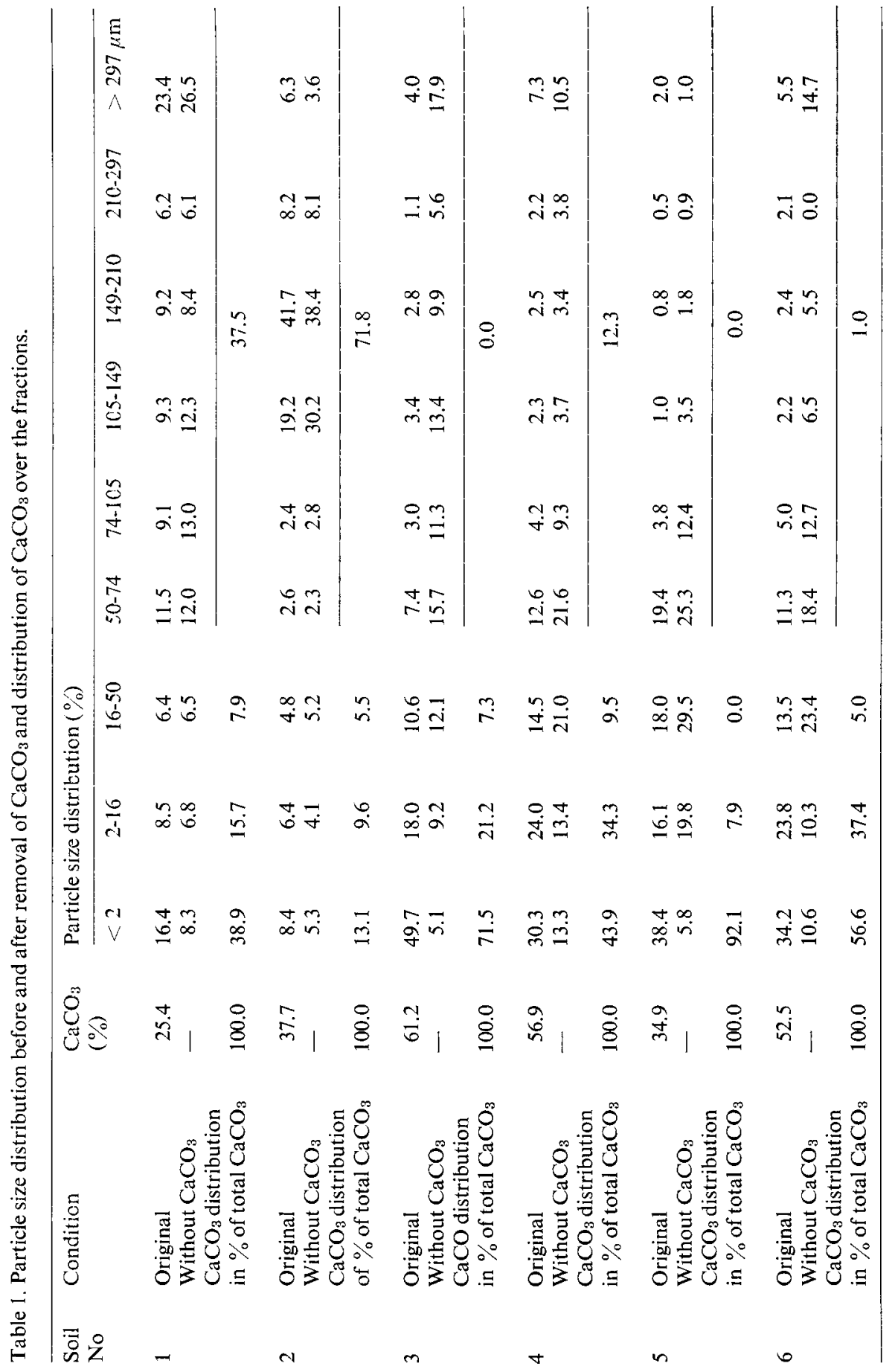


It appears that 88 to $100 \%$ of the $\mathrm{CaCO}_{3}$ in the heavier soils 3 to 6 is present in the clay and silt fraction, of which the clay fraction contains the highest amount of $\mathrm{CaCO}_{3}$. Although other calcareous soils from the Amariya region ranging from sandy loam to silty clay contained also more than $75 \%$ of the total amount of $\mathrm{CaCO}_{3}$ in the clay and silt fraction, the majority of the $\mathrm{CaCO}_{3}$ in these soils was within the silt fraction (UNDP/FAO, 1965, Vol. 4, App. 2). It seems that the $\mathrm{CaCO}_{3}$ in the heavier soils is present as a very fine or even colloidal constituent.

The $\mathrm{CaCO}_{3}$ in sandy loam 1 is rather regularly distributed over the clay, silt and sand fraction. In the loamy sand $2,72 \%$ of the $\mathrm{CaCO}_{3}$ is within the sand fraction.

\section{Moisture retention}

It was found that the structure of the high calcareous soils investigated here was only slightly modified by compaction: dry bulk densities could only be increased with 0.04 to $0.14 \mathrm{~g}$ per $\mathrm{cm}^{3}$. Also the moisture retention values of these soils did not show remarkable differences after compaction. This appears to be in accordance with the phenomenon that in incompressible soils - which include sands and materials as chalk and limestone - the internal pressures arising from foundation loads or overburden are transmitted by intergranular contacts and do not contribute to the pore-water pressure (Croney \& Coleman, 1954).

The moisture retention curves of all soils - with and without $\mathrm{CaCO}_{3}$ - are shown in Fig. 2. Total porosity, field capacity - for which the approximate value $\mathrm{pF} 2.0$ has been taken -, wilting percentage ( $\mathrm{pF} 4.2$ ) and dry bulk density (mass of dry soil per unit bulk volume) are noted in Table 2 . In the same table the aeration porosity and the readily available water capacity has been included. Generally it is stated that soils largely composed of attapulgite show low bulk densities (Grim, 1962).

The removal of $\mathrm{CaCO}_{3}$ causes a marked decrease in dry bulk density accompanied with an increase in porosity. For the lighter soils 1 and 2 this is less pronounced than for the clay and clay loam soils 3 to 6 . It seems that the removal of $\mathrm{CaCO}_{3}$ present in the pores between the soil particles, as well as the shift in texture towards a more sandy character, raises the porosity.

The moisture retention curves ( $\mathrm{pF}$-curves) generally show an increase in moisture content over the whole range of suctions when the $\mathrm{CaCO}_{3}$ has been removed, particularly for soils 3 to 6 . However, the moisture contents of the loamy sand 2 differ only slightly in the range $\mathrm{pF} 1.6-4.2$. This may result from the fact that the clay and silt fractions in this soil hardly differ before and after the removal of $\mathrm{CaCO}_{3}$.

The moisture retention curves of the soils without $\mathrm{CaCO}_{3}$ run more or less parallel to the curves of the original soils. This means that, though the total amount of pores increased considerably by the removal of $\mathrm{CaCO}_{3}$ (Table 2), the relative pore size distribution changed only slightly. Not only the water retained in the larger pores at lower suctions, but also that retained in the smaller pores at higher suctions, increased by the removal of $\mathrm{CaCO}_{3}$.

For soils 3 and 6 the aeration porosity and the available water capacity are hardly influenced by the removal of $\mathrm{CaCO}_{3}$. However, for the clay loams 4 and 5 decalcifi- 

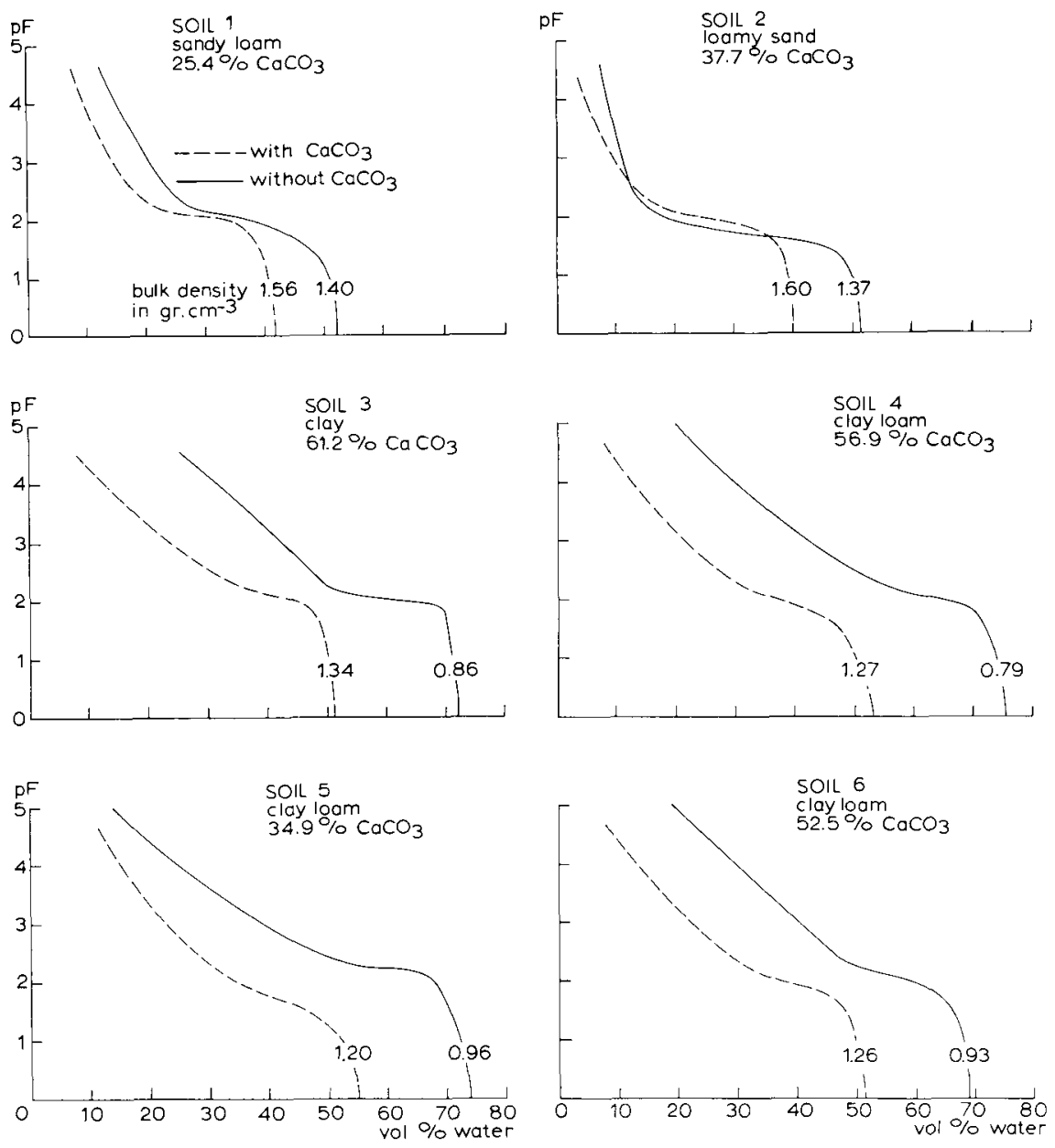

Fig. 2. Moisture retention curves of soils with and without $\mathrm{CaCO}_{3}$.

cation diminishes the aeration porosity and increases the available water capacity, due to its greater effect on the moisture content at $\mathrm{pF} 2.0$ than on the wilting percentage ( $\mathrm{pF} 4.2$ ) (Table 2).

The removal of $\mathrm{CaCO}_{3}$ doubles the aeration porosity for the sandy loam 1 and the loamy sand 2. In the absence of $\mathrm{CaCO}_{3}$ the available water capacity in soil 1 hardly shows any change, while for soil 2 this value is halved. Although soil 2 has a higher $\mathrm{CaCO}_{3}$ content than soil 1 the moisture contents at each applied suction of soil 1 are higher than those of soil 2. It seems that the distribution of both particle sizes and $\mathrm{CaCO}_{3}$ over the fractions is more important for the moisture-holding properties than the $\mathrm{CaCO}_{3}$ content itself. This is also clearly shown in comparing 
W. P. STAKMAN AND B. G. BISHAY

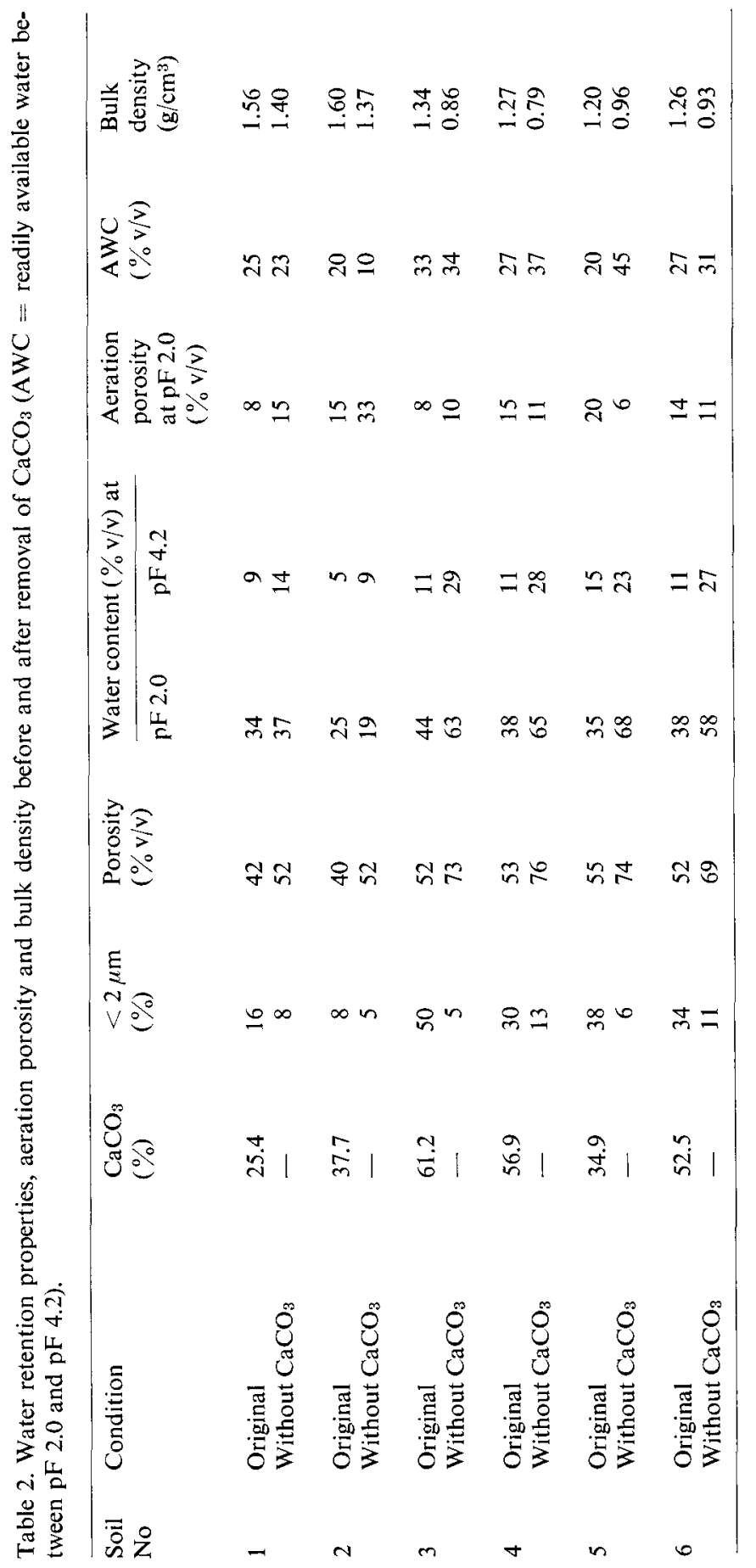


the loamy sand 2 with the clay loam 5 , which have almost the same $\mathrm{CaCO}_{3}$ content but a different distribution over the fractions (Table 1).

The phenomenon that by the removal of $\mathrm{CaCO}_{3}$, inspite of the then lower clay contents (Table 1), the surface area of the particles available for the adsorption of water seems to increase, may be explained by a change in the clay mineral attapulgite itself. In the natural state attapulgite is of fibrous texture; the individual fibres are fairly tightly held together in bundles (Grim, 1962). The mineral shows a chain structure and so-called zeolitic characteristics, i.e. it can hold water in micro-channels $(0.40$ to $0.65 \mathrm{~nm})$ which are present within the structure itself (Brown, 1961). As work is applied to the mass of such bundles (e.g. by solving the $\mathrm{CaCO}_{3}$ by means of a dilute acid) the individual fibres are separated. The total quantity of single fibres then may show a much greater surface area than the original bundles.

In the medium- and fine-textured soils the calcium seems not only to have a cementing effect on the soil particles, but to form probably also an integral part of the attapulgite structure (Weaver \& Pollard, 1973). Removal of $\mathrm{CaCO}_{3}$ can cause important structural changes as well in the clay mineral itself as in the structure of the soil, as is clearly shown by the shift in moisture retention curves.

\section{Consistency limits}

Soil consistency is usually defined as a term to designate the manifestations of the physical forces of cohesion and adhesion acting within the soil at various moisture contents (Baver et al., 1972). Some moisture-depending consistency states were defined by Atterberg (1911) and were later treated on their merits by Casagrande (1932).

The liquid limit (or upper plastic limit) of a clay is regarded as that water content at which sufficient water is present to allow clay particles to slip past one another under a certain applied force (Warkentin, 1961). It can also be defined in terms of shear strength or shortly as the water content at which, in the remoulded state, a clay passes from the plastic to an almost liquid state (Skempton, 1970).

Another Atterberg value is the plastic limit (or lower plastic limit) definable as the minimum weight percentage of moisture at which a soil can be deformed without rupture or as the water content at which the remoulded clay passes from the plastic to a friable or brittle condition (Skempton, 1970).

The numerical difference between the liquid limit and the plastic limit is known as the plasticity index (or plasticity number) and indicates the moisture range over which a clay is plastic.

Particularly during the last twenty years attempts have been made to put these empirical, but quantitative, Atterberg indices, which are particularly used for soil classification and soil engineering purposes, on a more physical basis. The use of these indices for the description of soil structure has been investigated by, among others, Boekel \& Peerlkamp (1956) and Boekel (1958).

Direct correlations between Atterberg limits and moisture retention curves have been examined by Uppal (1966) and Livneh et al. (1970). It seemed worthwhile to make such an attempt for calcareous soils too. 
W. P. STAKMAN AND B. G. BISHAY

Table 3. Liquid limit, plastic limit, plasticity index and clay activity of highly calcareous soils.

\begin{tabular}{lllllll}
\hline Soil No & $\begin{array}{l}\mathrm{CaCO}_{3} \\
(\%)\end{array}$ & $\begin{array}{l}\text { Clay } \\
<2 \mu \mathrm{m}(\%)\end{array}$ & $\begin{array}{l}\text { Liquid } \\
\text { limit }\end{array}$ & $\begin{array}{l}\text { Plastic } \\
\text { limit }\end{array}$ & $\begin{array}{l}\text { Plasticity } \\
\text { index }\end{array}$ & Activity \\
1 & 25.4 & 16 & 22.5 & 15.7 & 6.8 & 0.41 \\
3 & 61.2 & 50 & 34.6 & 18.0 & 16.6 & 0.24 \\
4 & 56.9 & 30 & 35.9 & 20.9 & 15.0 & 0.50 \\
5 & 34.9 & 38 & 40.8 & 18.6 & 22.2 & 0.58 \\
6 & 52.5 & 34 & 35.2 & 19.3 & 15.9 & 0.46 \\
\hline
\end{tabular}

The limits in Table 3 are means of the results obtained in two laboratories. The difference in results from the two laboratories ranged for the liquid limit from 0.3 to $5.3 \%(\mathrm{w} / \mathrm{w})$ of moisture (mean difference $3.0 \%)$ and for the plastic limit from 0.8 to $3.3 \%(\mathrm{w} / \mathrm{w}$ ) of moisture (mean difference $2.1 \%$ ).

These differences are small in view of the fact that the limit values of attapulgite may vary a great deal depending on the preparation (e.g. puddling) of the samples before the determination, that may disintegrate the bundles of fibres in the clay mineral.

In comparison with data given in literature the figures for these attapulgite soils seem to be low. Partly this may be attributed to the air-dryness of the samples since drying out tends to lower the limit values (Grim, 1962). The presence of other clay minerals and of carbonates, of which not only the total amount of $\mathrm{CaCO}_{3}$ but also the distribution of $\mathrm{CaCO}_{3}$ over the particle fractions is to be considered, will also influence the plasticity limits.

It should be stressed that not only the type of clay mineral influences the adsorption of water by the colloidal system but that there can also be a wide variability in Atterberg limits between different samples of the same clay mineral, due to differences in mineral structure, in the nature of exhangeable cations and in the effect of larger particles (Baver et al., 1972; Grim, 1962).

Another complication is that a higher amount of $\mathrm{CaCO}_{3}$ doet not need to imply a greater surface area. Thus Holford \& Mattingly (1975) found for limestone soils in southwest England that the surface area of $\mathrm{CaCO}_{3}$ was an inverse function of the $\mathrm{CaCO}_{3}$ percentage.

It appears from Table 3 that the liquid limit increases with increasing clay content up to at least $30-40 \%$ clay. The plastic limit stays rather constant, so the plasticity index shows thte same tendency as the liquid limit.

The liquid limit increases considerably with increasing $\mathrm{CaCO}_{3}$ content up to about $35 \%$ of $\mathrm{CaCO}_{3}$. The plastic limit shows a slight increase with increasing $\mathrm{CaCO}_{3}$ content, so also here the plasticity index follows the trend as the liquid limit.

Skempton (1970) classifies clays with $\mathrm{CaCO}_{3}$ contents below $25 \%$, having liquid limits between 30 and 50 and plasticity indices between 10 and 30, into the group of low plasticity. According to these limits the highly calcareous soils can be placed in the same category.

According to the position of the soils towards the A-line on the Casagrande plasti- 


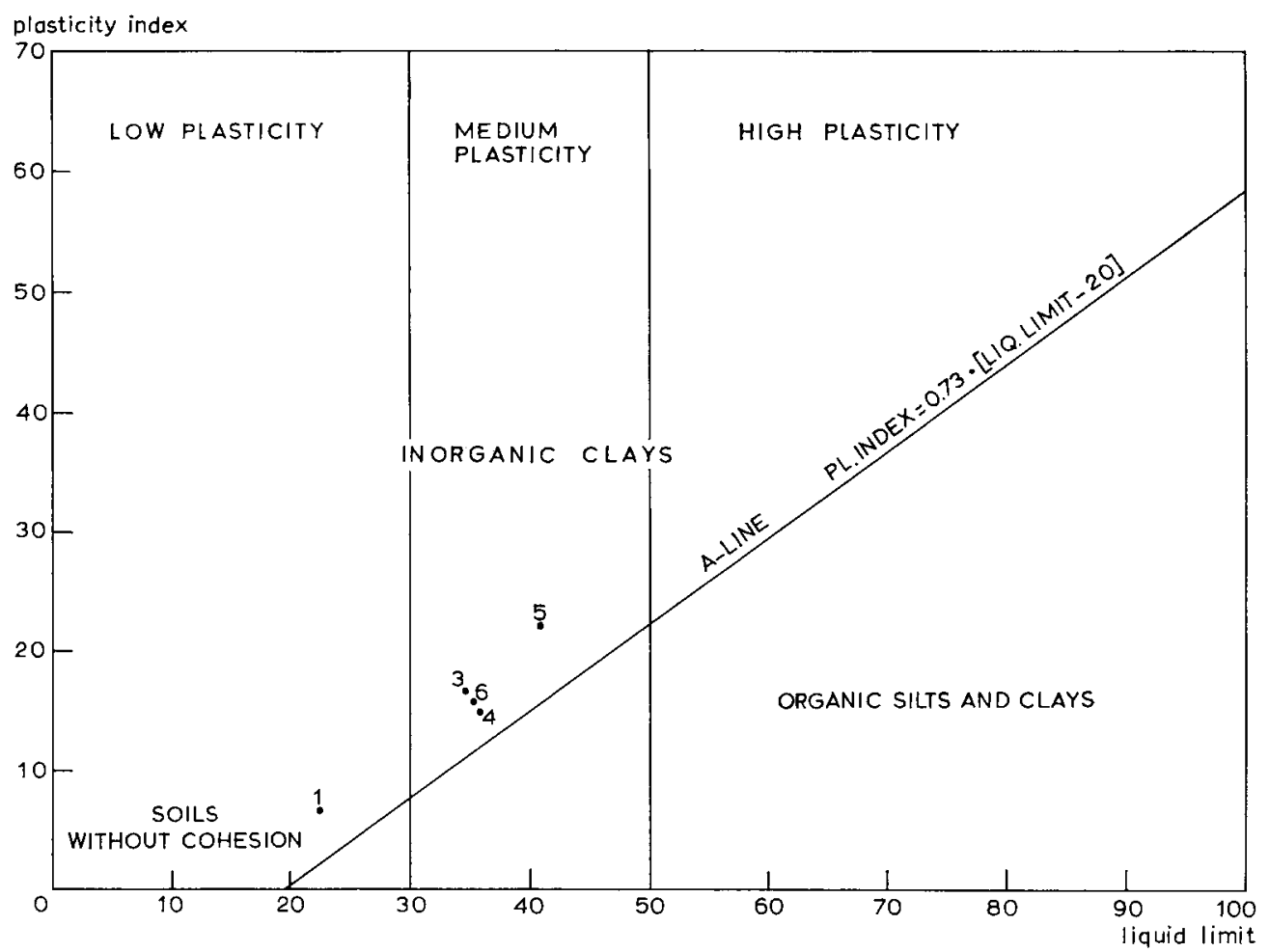

Fig. 3. Highly calcareous soils on the plasticity chart after Casagrande (1948).

city chart (Fig. 3) the investigated highly calcareous soils mostly belong to the medium plasticity group. This chart, widely used in soil engineering practice for characterizing the plastic properties of fine-grained soils, is a plot of the plasticity index against the liquid limit. This line was originally drawn as an empirical boundary between inorganic clays and organic silts and clays (Casagrande, 1948; Towner, 1974).

The low plasticity of the sandy loam 1 (lowest clay and $\mathrm{CaCO}_{3}$ content) was to be expected. In spite of the highest clay and $\mathrm{CaCO}_{3}$ content of soil 3 , its position with regard to the A-line does not significantly differ from that of the clay loams 4 and 6 . There also is no direct explanation for the relatively high limits of clay loam 5. The fact that more than $90 \%$ of the total amount of $\mathrm{CaCO}_{3}$ in this soil is within the clay fraction, may play a role (Table 1 ).

A common value to indicate the plasticity index of the clay fraction of the soil is the clay activity which is the ratio of the plasticity index and the clay fraction percentage (Table 3). In comparison with clay activities published by Grim (1962) for attapulgite ( 0.57 to 1.23 ), the highly calcareous soils with the predominating clay mineral attapulgite show rather low activities. According to Skempton (1953) the 
Table 4. Soil moisture tension (pF) at liquid limit and plastic limit conditions.

\begin{tabular}{|c|c|c|c|c|c|c|}
\hline \multirow[t]{2}{*}{ Soil No } & \multirow{2}{*}{$\begin{array}{l}\mathrm{CaCO}_{3} \\
(\%)\end{array}$} & \multirow{2}{*}{$\begin{array}{l}\text { Clay } \\
<2 \mu \mathrm{m}(\%)\end{array}$} & \multicolumn{2}{|c|}{ Liquid limit } & \multicolumn{2}{|c|}{ Plastic limit } \\
\hline & & & $\% \mathrm{w} / \mathrm{w}$ & $\mathrm{pF}$ & $\% w / w$ & $\mathrm{pF}$ \\
\hline 1 & 25.4 & 16 & 22.5 & 1.9 & 15.7 & 2.2 \\
\hline 3 & 61.2 & 50 & 34.6 & 1.9 & 18.0 & 3.1 \\
\hline 4 & 56.9 & 30 & 35.9 & 1.6 & 20.9 & 2.5 \\
\hline 5 & 34.9 & 38 & 40.8 & 1.3 & 18.6 & 3.0 \\
\hline 6 & 52.5 & 34 & 35.2 & 1.8 & 19.3 & 2.8 \\
\hline
\end{tabular}

investigated soils would all belong to the inactive clays (activity smaller than 0.75 ) indicating that internal friction is more responsible for strength than cohesion.

\section{Consistency and soil moisture tension}

\section{Liquid limit-pF relationship}

For the highly calcareous soils investigated the moisture tensions at liquid limit condition were read from the $\mathrm{pF}$ curves (after conversion of weight percentage into volume percentage of moisture by multiplication with the dry bulk density of the pF samples).

The results are given in Table 4. The corresponding $\mathrm{pF}$ values vary from 1.3 to 1.9 (mean $\mathrm{pF}$ 1.7). Lower $\mathrm{pF}$ values at the liquid limit are mentioned by Croney \& Coleman (1954), who found $\mathrm{pF}$ values of 0.8 and 0.5 for a compressible heavy clay soil and a partially compressible light clay soil. Graecen (1960) states that for clay and clay loam soils with clay contents ranging from 38 to $71 \%$ the liquid limit tension did not exceed $\mathrm{pF}$ 1.0. Comparison of these results is problematic because of the quite different pre-treatment of the soil samples.

The $\mathrm{pF}$ values for the investigated calcareous soils all lie within the flex range of the curve indicating the transition from a saturated to an unsaturated condition. This agrees well with the (inverted) definition for the liquid limit as the transition from the almost liquid to the plastic state of a clay soil.

\section{Plastic limit-pF relationship}

In the same way as done for the liquid limit the $\mathrm{pF}$ values for the plastic limits were read from Fig. 2 and noted in Table 4. The $\mathrm{pF}$ values at the plastic limit range from 2.1 to 3.0 (mean pF 2.7). These figures are in the same order of magnitude as the $\mathrm{pF}$ value of 2.82 found by Graecen (1960) at the plastic limit of clay aggregates and as the $\mathrm{pF}$ values of 2.6 and 3.3 found by Croney \& Coleman (1954) on the drying curve of a light and a heavy clay soil, respectively.

On the other hand, Uppal (1966) published values of pF 1.5 on the drying curve and $\mathrm{pF} 0.5$ on the wetting curve for soils compacted to a dry bulk density of $1.60 \mathrm{~g} / \mathrm{cm}^{3}$ with plastic limits ranging from 17 to $34 \%(\mathrm{w} / \mathrm{w})$ of moisture.

Uppal's figures seem not only low in comparison with the afore-mentioned $\mathrm{pF}$ 
Table 5. Plasticity index and corresponding $\mathrm{pF}$ values.

\begin{tabular}{llll}
\hline Soil No & $\begin{array}{l}\text { Plasticity index } \\
(\% \mathrm{w} / \mathrm{w})\end{array}$ & $\begin{array}{l}\text { Moisture tension }(\mathrm{pF}) \\
\text { from fig. } 3\end{array}$ & $\begin{array}{l}\text { according to } \\
\text { Livneh et al. (1970) }\end{array}$ \\
& & & 3.8 \\
1 & 6.8 & 3.8 & 3.1 \\
4 & 16.6 & 3.2 & 3.2 \\
5 & 15.0 & 3.3 & 3.0 \\
6 & 22.2 & 2.6 & 3.2 \\
\hline
\end{tabular}

values but also in view of the following consideration. At plastic limit the amount of oriented water is probably in the order of 5 to 10 molecular layers (Grim, 1962). For soil particle fractions between 1 and $100 \mu \mathrm{m}$ from the A-horizont of a chernozem, 5 to 10 molecular layers of water corresponded with tension values of $\mathrm{pF} 4.2$ and 2.5, respectively (Michurin \& Lytayev, 1967). The $\mathrm{pF}$ values of 2.1 to 3.0 found for the investigated calcareous soils fall within this range.

\section{Plasticity index- $p F$ relationship}

A linear correlation between the logarithm of the plasticity index and the corresponding moisture tension $(\mathrm{pF})$ on the drying curve was found by Livneh et al. (1970). They deduced the following relationships for different soil classes: a) sandy loam: $\mathrm{pF}=4.12-0.42 \log \mathrm{PI}(\mathrm{PI}=$ plasticity index $)$; b) silty clay loam, silty loam: $\mathrm{pF}=4.64-1.24 \log \mathrm{PI}$; c) clay: $\mathrm{pF}=4.35-1.03 \log \mathrm{PI}$.

For the investigated highly calcareous soils formula a was used for sandy loam 1 , formula $b$ for clay loams 4,5 and 6 and formula $\mathrm{c}$ for clay 3 .

In Table 5 the plasticity indices and the corresponding $\mathrm{pF}$ values obtained from the curves in Fig. 2 as well as derived from Livneh's formulas are noted. With the exception of clay loam 5 these $\mathrm{pF}$ values agree well, indicating that the plasticity index also of highly calcareous soils can be predicted with the aid of the moisture retention curves.

Efforts to obtain reproducible plasticity limits of the soils after decalcification failed. In spite of the considerably lower clay content of the soils without $\mathrm{CaCO}_{3}$ their liquid and plastic limits, as far as determinable, all showed greater values than for the same soils with $\mathrm{CaCO}_{3}$. A possible explanation, as already mentioned in the paragraph on moisture retention, would be that by decalcification a disintegration of the attapulgite mineral occurs which enlarges the adsorptive surface areas of the soil.

\section{Some remarks on moisture condition}

Although only tentative conclusions can be drawn from the results of the six soil samples investigated and adequate checks and comparisons with the same type of 
soils in other regions are hardly possible (cf. de Meester, 1970), the moisture retention values give some indications with regard to their moisture conditions.

Generally it is not possible to relate field capacity to a specific suction value since this relation is not only dependent on the water-retaining properties but also on the water-transmitting conditions where the depth of the water-table and the stratification of the profile play a role. The choice of $\mathrm{pF} 2.0$ for field capacity, therefore, is arbitrary. The authors also are aware of the fact that the readily available water capacity taken between $\mathrm{pF} 2.0$ and $\mathrm{pF} 4.2$ may be too extended, and that water may only be easily consumed by crops between pF 2 and somewhere between pF 3 and pF 4.2.

Putting aside these restrictions Table 2 indicates that all the investigated highly calcareous soils have a favourable available water capacity (above $20 \% \mathrm{v} / \mathrm{v}$ ). The sandy loam (soil 1) and the clay (soil 3) seem to have limiting aeration conditions at $\mathrm{pF} 2$ since for an optimal root development the aeration capacity should be at least about $15 \%(\mathrm{v} / \mathrm{v})$. Sophisticated irrigation management (small quantities of water with short intervals) seems to be required.

Since field capacity conditions of the calcareous soils do not differ to a great extent from the liquid limit values (Table 4), slaking may occur after irrigation (Boekel \& Peerlkamp, 1956). Also for this reason irrigation should be checked constantly.

\section{References}

Atterberg, A., 1911. Die Plastizität der Tone. Int. Mitt. Bodenk. 1: 10-43.

Baver, L. D., W. H. Gardner \& W. R. Gardner, 1972. Soil physics, 4th ed. John Wiley, New York.

Black, C. A. (Ed.), 1965. Methods of soil analysis, Part 1: Agronomy 9: 391-399. American Society of Agronomy.

Boekel, P., 1958. Evaluation of the structure of clay soils by means of soil consistency. Proc. int. Symp. Soil Structure (Ghent, Belgium).

Boekel, P. \& P. K. Peerlkamp, 1956. Soil consistency as a factor determining the soil structure of clay soils. Neth. J. agric. Sci. 4: 122-125.

Brown, G., 1961. The X-ray identification and crystal structures of clay minerals. Mineralogical Society, London.

Casagrande, A., 1932. Research on the Atterberg limits of soils. Public Roads 13: 121-120.

Casagrande, A., 1948. Classification and identification of soils. Trans. Am. Soc. civ. Engrs 113: 901-930.

Croney, D. \& J. D. Coleman, 1954. J. Soil Sci. 5 (1) 75-84.

Deb, B. C. \& S. P. Chadha, 1970. Mechanical analysis of calcareous soils and distribution of calcium carbonate in various fractions. J. Indian Soc. Soil Sci. 18 (3) 227-232.

Elgabaly, M. M., 1962. The presence of attapulgite in some soils. Soil Sci. 93: 387-389.

Graecen, E. L., 1960. Aggregate strength and soil consistence. Trans. 7th int. Congr. Soil Sci. (Madison, Wisc., USA), Vol. 1: 256-264.

Grim, R. E., 1962. Applied clay mineralogy. McGraw-Hill, New York.

Holford, I. C. R. \& G. E. B. Mattingly, 1975. Surface areas of calcium carbonate in soils. Geoderma 13: 247-255.

Labib, F. \& C. Sys, 1970. Soils on lacustrine and marine deposits in the United Arab Republic. Pedologie 20 (3) 381-403.

Lambe, T. W., 1960. Soil testing for engineers, 6th ed. John Wiley, New York, pp. 22-28.

Livneh, M., J. Kinsky \& D. Zaslavsky, 1970. Correlation of suction curves with the plasticity index of soils. J. Mat. 5 (1) 209-220. 


\section{MOISTURE RETENTION AND PLASTICITY OF HIGHLY CALCAREOUS SOILS}

McLean, S. A., B. L. Allen \& J. R. Graig, 1972. The occurrence of sepiolite and attapulgite in the southern high plains. Clays Clay Minerals 20 (3) 143-150.

Meester, T. de, 1971. Highly calcareous lacustrine soils in the Great Konya Basin, Turkey. Pudoc, Wageningen.

Michurin, B. N. \& I. A. Lytayev, 1967. Relations between moisture content, moisture tension and specific area in soil. Sov. Soil Sci. 8: 1093-1103.

Millot, G., 1964. Geologie des Argiles. Masson, Paris.

Richards, L. A. (Ed.), Diagnosis and improvement of saline and alkaline soils. Agriculture Handbook No 60. USDA. US Government Printing Office, Washington, D.C.

Skempton, A. W., 1953. The colloidal activity of clays. Proc. 3rd int. Conf. Soil Mech. (Zürich), Vol. 1: 57-61.

Skempton, A. W., 1970. The consolidation of clays by gravitational compaction. Q. J. Geol. Soc. Lond. 125: 373-411.

Stakman, W. P. \& G. G. van der Harst, 1969. Determination of soil moisture retention curves. 1. Sand-box apparatus. Institute for Land and Water Management Research (ICW), Wageningen.

Stakman, W. P., G. A. Valk \& G. G. van der Harst, 1969. Determination of soil moisture retention curves. 2. Pressure membrane apparatus. Institute for Land and Water Management Research (ICW), Wageningen.

Towner, G. D., 1974. A note on the plasticity limits of agricultural soils. J. Soil Sci. 25 (3) 307-309.

UNDP/FAO, 1965. Report FAO/SF: 16/UAR.

Uppal, H. L., 1966. A scientific explanation of the plastic limit of soils. J. Mat. 1 (1) 164-179.

Warkentin, B. P., 1961. Interpretation of the upper plastic limit of clays. Nature, Lond. 190 (4772) 287-288.

Weaver, C. E. \& L. D. Pollard, 1973. The chemistry of clay minerals. In: Developments in sedimentology No 15: 119-126. Elsevier, Amsterdam. 